\title{
A Progress Report on the Characterization and Modeling of a Very Flexible Wind Turbine Design
}

Neil D. Kelley

Alan D. Wright

Richard M. Osgood

National Wind Technology Center

National Renewable Energy Laboratory

Presented at

ASME/AIAA Wind Energy Symposium

Reno, Nevada

January 11-14, 1999

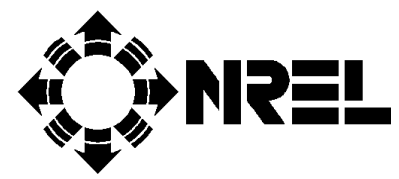

National Renewable Energy Laboratory 1617 Cole Boulevard Golden, Colorado 80401-3393

A national laboratory of the U.S. Department of Energy Managed by Midwest Research Institute for the U.S. Department of Energy under contract No. DE-AC36-83CH10093

Work performed under task number WE901010

October 1998 


\section{NOTICE}

This report was prepared as an account of work sponsored by an agency of the United States government. Neither the United States government nor any agency thereof, nor any of their employees, makes any warranty, express or implied, or assumes any legal liability or responsibility for the accuracy, completeness, or usefulness of any information, apparatus, product, or process disclosed, or represents that its use would not infringe privately owned rights. Reference herein to any specific commercial product, process, or service by trade name, trademark, manufacturer, or otherwise does not necessarily constitute or imply its endorsement, recommendation, or favoring by the United States government or any agency thereof. The views and opinions of authors expressed herein do not necessarily state or reflect those of the United States government or any agency thereof.

Available to DOE and DOE contractors from:

Office of Scientific and Technical Information (OSTI)

P.O. Box 62

Oak Ridge, TN 37831

Prices available by calling (423) 576-8401

Available to the public from:

National Technical Information Service (NTIS)

U.S. Department of Commerce

5285 Port Royal Road

Springfield, VA 22161

(703) 487-4650 
AIAA-90-0052

\title{
A PROGRESS REPORT ON THE CHARACTERIZATION AND MODELING OF A VERY FLEXIBLE WIND TURBINE DESIGN*广
}

\author{
Neil D. Kelley, $\$$ Alan D. Wright, Richard M. Osgood \\ National Wind Technology Center \\ National Renewable Energy Laboratory \\ Golden, Colorado
}

\begin{abstract}
The combination of increasing turbine rotor diameters and the desire to achieve long lifetimes has placed increased emphasis on understanding the response of flexible turbine structures in a turbulent inflow environment. One approach to increase fatigue lifetimes has been to design structures that can either shed or adequately absorb turbulent loads through the use of flexible rotors and support towers, and hubs and nacelles that exhibit multiple degrees of angular freedom. The inevitable result in such designs is a substantial increase in dynamic complexity. In order to develop a sufficient knowledge of such concepts, extensive measurements coupled with detailed analytical simulations of a flexible turbine design are required. The Wind Eagle 300 turbine, with its lightweight flexible rotor and hub, meets these criteria and is currently being investigated.

In this paper we discuss a few early results from our recently completed field measurement effort. We found that the turbine rotor response was dominated by a onceper-revolution oscillation that was responsible for large cyclic variations in the output power. The available evidence points to a rotor imbalance related to structural differences in one of the blades and a misalignment of the pitch angles. We also compared the variation in mean out-of-plane bending loads with wind speed with a conventional rigid hub design.
\end{abstract}

\section{INTRODUCTION}

One of the consequences of the increased rotor diameters on the latest turbine designs is the continued increase in turbulence-induced loads with mean wind speed. The accompanying rise in fatigue loads, associat-

\footnotetext{
* This work is supported by the U.S. Department of Energy under contract no. DE-AC36-83CH10093.

† This paper is declared a work of the U.S. Government and is not subject to copyright protection in the United States.

†Senior Member, AIAA.
}

ed with larger (and softer) rotors using relatively rigid blades and hubs ultimately limits the available lifetime. One approach to reduce loads is to soften the structure in such a way that the affected components move and reduce the induced stresses. Such an avenue may not only reduce stresses and therefore fatigue, but also allow the structure to be constructed of lighter and perhaps less expensive components. An unavoidable consequence of such a design approach is the need to isolate and understand the complex, interacting dynamics inherent in flexible rotating structures being excited by a wide range of turbulent loading conditions.

In 1996, the NWTC, in collaboration with researchers at the Sandia National Laboratory, undertook a program to procure, instrument, measure, model, and interpret the response of a very flexible turbine to turbulence excitation. We chose the Wind Eagle 300 turbine for this purpose because it is one of the most flexible designs available, if not the most flexible.

The program, as originally planned, had three phases. The first phase included, after choosing a specific turbine, the assembly of a very detailed inventory of the target turbine's physical properties down to the component level including mass and stiffness distributions and mechanical damping (when available). Also during this phase, component and sub-assembly vibrational modes would be established through in-situ, full-scale modal testing. From this information, analytical models of the turbine system would be developed.

The second phase of the program would include turbine instrumentation and taking a limited, but detailed, series of atmospheric measurements in order to collect information to validate and refine the analytical models developed under the initial phase.

During the final phase, areas of uncertainty would be identified where additional information was necessary for resolution (or at least isolation). The purpose this last phase, then, would be to perform a series of both static and atmospheric measurements that were 
highly targeted to answering these questions and improving our knowledge of flexible turbine dynamics. Unfortunately, the program was scaled back to essentially include only the first two phases.

With the support and assistance of the Cannon Wind Eagle Corporation, we reported on the progress made during the initial phase of the program in Kelley et al. ${ }^{1}$ In this paper we discussed the results of the detailed physical property inventorying, component and fullscale modal testing, and our initial analytical model development. We noted at the time that our initial modeling confirmed our expectation that the response of this turbine to turbulence excitation would be complex and its understanding a challenge. We found that it is not always possible to anticipate an entire range of responses to a configuration change without first performing a representative numerical simulation for guidance. We also learned from both our full-scale modal testing and analytical modeling that accurate measurements of not only the modal response were important but also of the operational stresses, accelerations, displacements, and angular motions.

The measurement of the low frequencies of the first few fundamental mode shapes, which are very important to understanding fatigue damage accumulation, were a challenge because of the need to have accurate accelerometer amplitude and phase responses below 1 Hz. We determined that the overall response bandwidth of the turbine dynamics was very wide when compared with much more rigid turbine designs. For the Wind Eagle prototype we tested, it ranges from about 0.45 to $25 \mathrm{~Hz}$.

In this paper we present an overview of our progress towards the objectives below. We specifically discuss some early results of our limited, but reasonably detailed, measurements taken on the Wind Eagle turbine under a range of atmospheric conditions at the NWTC during May and early June 1998. The status of the development of our baseline analytical model of the Wind Eagle turbine is reviewed and discussed by Wright et al. ${ }^{2}$

\section{OBJECTIVES}

Our specific objectives for this overall effort are to:

- Document the physical properties of the turbine's component (mass and stiffness distributions) and to determine their mechanical damping wherever possible

- Establish component, sub-assembly, and the complete system vibration modes through in-situ, fullscale modal analyses

- Summarize this information and develop analytical simulations of the turbine dynamics for turbulent inflows using the ADAMS ${ }^{\S},{ }^{, 3}$ and FAST_AD, $\uparrow, 4,5$ dynamic analysis codes for wind turbines

- Compare numerical simulations using limited operational measurements to assess the level of our ability to analytically reproduce and understand the observed turbine dynamic responses

- Use these results to contribute to the development of a detailed plan for a comprehensive test of a turbine for validating our current design codes and their ability to predict extreme events that determine turbine fatigue lifetimes.

\section{THE NWTC WIND EAGLE TURBINE}

The Wind Eagle turbine used for this program is one of the latest descendants of lightweight, flexible turbines designed by Jay Carter, Sr. Many features of this machine have their origins in the Carter 25 turbine designed in the 1970s. Departing from earlier Carter teetered-hub designs, the Wind Eagle nacelle is suspended directly over the tower and can move about both the yaw and tilt axes. Further, both blades are now pitched collectively replacing the individual-pitch mechanisms used in previous designs. A lightweight tiltdown, guyed tower that is similar to those used with the Eagle's predecessors has been retained.

The Wind Eagle turbine used for this program is a pre-production prototype model known as P1. It has an overall rotor diameter of $29.3 \mathrm{~m}$ (the longest so far developed for the Wind Eagle) and a nominal power rating of $300 \mathrm{~kW}$ at $16 \mathrm{~m} / \mathrm{s}$ in the NWTC environment. The hub height is $49.8 \mathrm{~m}$. The rotor consists of a continuous, flexible-beam or "flexbeam" spar with two blade shells attached. The inboard $81.5 \%$ of the shells incorporate a tapered LS(1) airfoil geometry while the remaining outer portion transitions to a constant-chord airfoil with an NREL S806A shape. The turbine is pictured in Figure 1 and the flexibility of its rotor is demonstrated in Figure 2.

\section{THE WIND EAGLE MEASUREMENT SYSTEM}

The measurement system used to collect and process a range of physical measurements from the Wind Eagle turbine has three major components: sensors, data recording or acquisition, and data processing subsystems. Two data acquisition systems were employed. One was mounted within the rotating portion of the turbine to acquire signals in that frame of

$\S_{\text {Automated Dynamics Analysis of Mechanical Systems. ADAMS is a regis- }}$ tered trademark of Mechanical Dynamics, Inc.

TVersion of the Fatigue, Aerodynamics, Structures, and Turbulence code that uses the University of Utah AeroDyn aerodynamics subroutine package to calculate blade aerodynamic forces. 


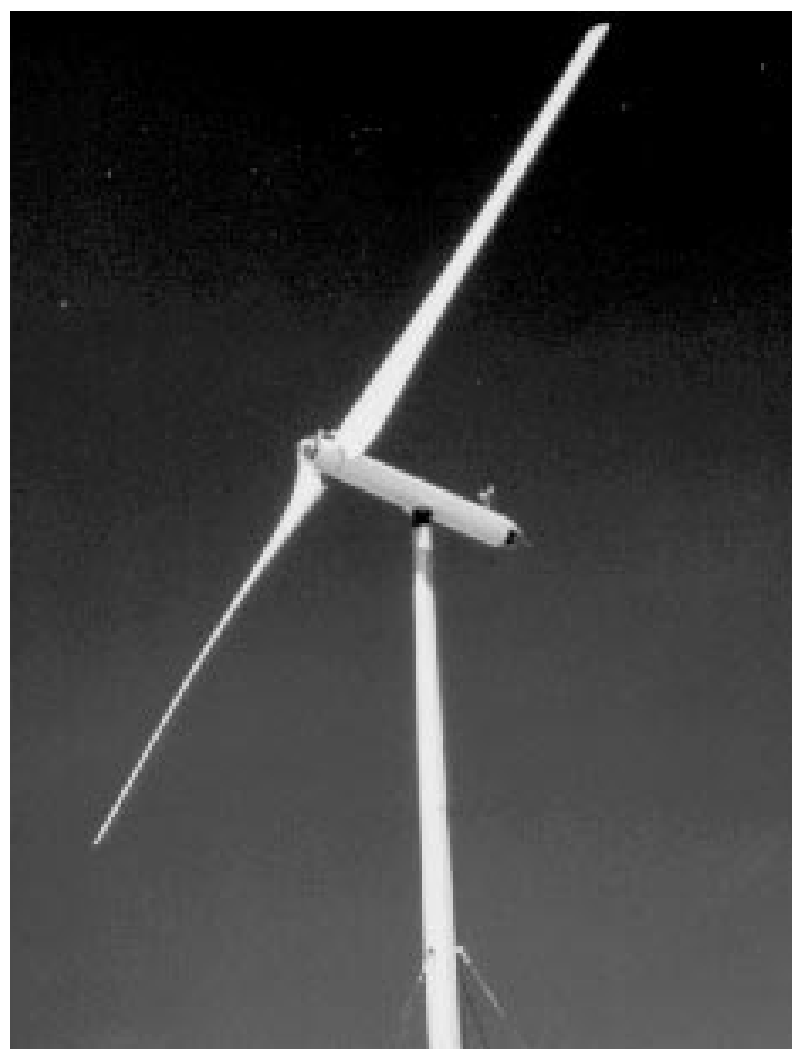

Figure 1. NWTC Wind Eagle 300 turbine.

reference. The other system recorded signals originating from the non-rotating frame and turbine support and meteorological towers. A $68-\mathrm{m}$ meteorological tower was located upstream of the turbine in the direction of the prevailing wind. We processed the collected data using the NWTC Sun Ultra-Sparc computing system and the GENeral Scientific Data PROcessor ${ }^{6}$ (developed by the National Center for Atmospheric Research) and the General Post-Processor ${ }^{7}$ (developed by the NWTC) software packages.

\section{Sensing Subsystem}

The sensing subsystem has three major divisions: a) the rotating frame; b) the fixed frame and support tower; and c) the meteorological tower.

Rotating frame. A total of 13 measurement signals were available within the rotating frame. Only nine of these signals could be recorded at one time. Full-bridge strain gages for measuring both in-plane (edgewise) and out-of-plane (flapping) root loads on both blades (designated as Blade A and B) are installed $0.56 \mathrm{~m}$ from the center of rotation. A full-bridge gage sensitive to flapping loads was installed on each of the blade shells or subspars immediately outboard of the joint connecting the blade shell to the flexbeam spar and $2.54 \mathrm{~m}$ from the center of rotation. Full-bridge strain gages were also mounted on the low-speed shaft to measure orthogonal components of the shaft bending loads and torque. The arms that connect the hydraulic actuator to the blade shell pitching mechanism were both instrumented with strain gages to measure in-line forces and bending loads. Finally, a solid-state proximity detector was positioned to provide a single, short pulse when Blade A was vertical and pointing down.

Early measurements revealed a strong once-perrevolution (1-P) oscillation in the generator output power and in many of the load signals. A decision was made to configure the sensing array to provide as many differential measurements as possible to fully assess the origins of these strong cyclic phenomena. The nine parameters measured in the primary data collection effort included the low-speed shaft torque, the 0-degree lowspeed shaft bending, the flexbeam spar root edgewise and flapping loads, and the blade shell or subspar flap loads.

The rotating-frame strain gages were calibrated using a specially constructed series of cabling and pulleys with calibrated load cells before and after the primary measurement period of mid-May to early June 1998. The gage sensitivities were determined from these calibrations. The drifts in the gage zero values or offsets were tracked within this period by measuring the gage output voltages at fixed rotor-azimuth positions when there was little or no wind. During periods of low velocity winds, the rotor was aligned parallel to the wind vector to remove the loading on the blades. A total of eight zero measurements were made between May 14 and June 1st. The zero drift over this period was found to be generally small. The uncertainties in engineering units for each of the bending load measurements for the primary measurement period (not including the $0^{\circ}$ lowspeed shaft bending) are summarized in Table 1. The

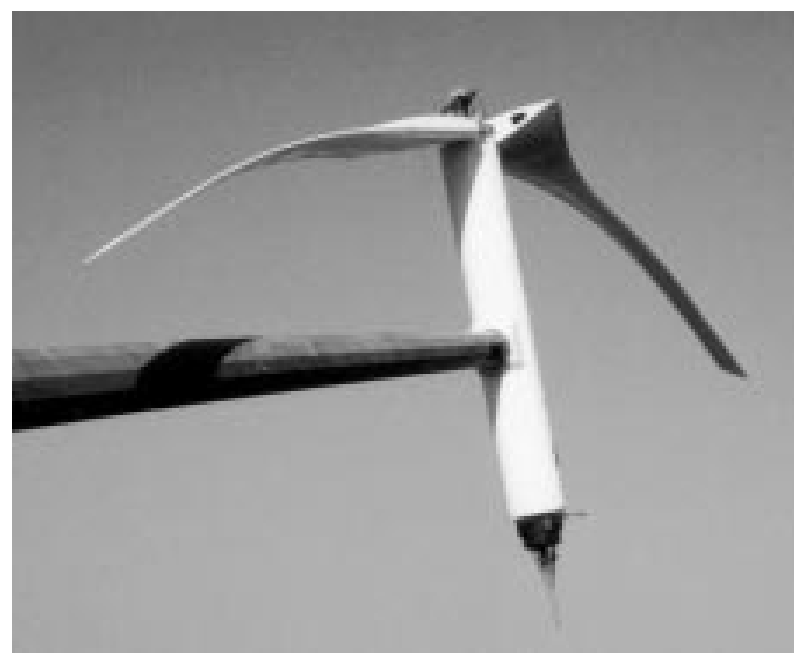

Figure 2. Demonstration of flexibility of Wind Eagle rotor blades. 
mean or characteristic standard error (one standard deviation uncertainty) for all is $0.28 \mathrm{kNm}$ whereas the $95 \%$ confidence level is $0.66 \mathrm{kNm}$. The largest source of error in these measurements was our lack of confidence that the rotor blades were absolutely horizontal and vertical when the readings were taken.

Non-rotating subsystem. Precision potentiometric transducers were used to measure the nacelle yaw and tilt angles. Three pairs of orthogonal strain gages were mounted on the support tower to measure the fore-aft and side-side bending moments at 21.9,33.5, and $40.6 \mathrm{~m}$ above the tower base (hinge pin). Tower torsion gages were installed at 3.5 and $46.6 \mathrm{~m}$ above the base, the later being immediately below the nacelle. Pairs of orthogonal, high-quality piezeoresistive accelerometers and inclinometers that exhibited a usable frequency response below $1 \mathrm{~Hz}$ were used to measure fore-aft and side-side motions at the tower top. Rugged, precision bridge amplifiers were used to condition the tower signals and were electrically re-zeroed each day during which data was collected. A power transducer individually calibrated and traceable to the National Institute of Standards and Technology (NIST) was used to measure the generator electrical output.

Meteorological tower. The 68-m meteorological tower was located $59 \mathrm{~m}$ upwind of the turbine in the direction of the prevailing wind. It was instrumented with cup anemometers and direction vanes at the 3-and 67-meter elevations. A three-axis, ultrasonic anemometer (Kaijo Model DA-600 with a $10 \mathrm{~Hz}$ bandwidth) was mounted at hub-height. The absolute air temperature was measured at the 3-m elevation and the temperature difference between 3 and $67 \mathrm{~m}$ using precision, 4-wire resistance temperature detectors and bridge signal conditioners. A precision, digital barometer measured the barometric pressure at the 3-m elevation.

\section{Data Acquistion Subsystems}

Two data acquisition systems were necessary to collect both rotating-frame and non-rotating frame and meteorological data for the Wind Eagle. The data bandwidth of $40 \mathrm{~Hz}$ and a sampling frequency of $200 \mathrm{~Hz}$ for the turbine-related signals was chosen based on the measured system upper frequency response of $25 \mathrm{~Hz}$ and the desire to provide time-series signals with minimal time domain distortion. This is particularly important for the application of various time-domain data analysis techniques such as rainflow cycle counting and windowed or wavelet decompositions.

Rotating frame. The rotating frame data was collected with a SoMat Model 2100 Field Computer. This unit, which consists of a number of stacked modules, included a microprocessor, dynamic memory, low-pass filters, signal conditioning and converters, and communication interfaces. A total of 9 channels (eight strain and one digital) were available. Each of the strain measurements was processed by two modules: a 6-pole Butterworth, low-pass filter and a combination bridge amplifier and 12-bit analog-to-digital converter. The once-per-revolution rotor azimuth marker was connected to the input of a combination input/output 6-bit digital module. The filter breakpoints were set to $40 \mathrm{~Hz}$ and each channel was sampled at 200 per second. The data was collected within the on-board memory and later transferred at the conclusion of each 10-minute collection period via a radio link to a personal computer for final storage.

Non-rotating frame. Each signal from the turbine nacelle, support tower, and meteorological tower were passed through a 4-pole, Butterworth low-pass filter. Each signal was sampled at 200 per second and quantized to 16 bits resolution by a Neff 470 data acquisition system and its associated personal computer (PC). The filter breakpoints for the turbine-related data were $40 \mathrm{~Hz}$

Table 1. Rotating Frame Load Measurement Uncertainties.

\begin{tabular}{|lcc|}
\hline PARAMETER & $\begin{array}{c}\text { STANDARD OR EXPECTED ERROR } \\
(\mathbf{k N m})\end{array}$ & $\begin{array}{c}\mathbf{9 5 \%} \text { CONFIDENCE LEVEL } \\
(\mathbf{k N m})\end{array}$ \\
\hline Low-Speed Shaft Torque & \pm 0.18 & \pm 0.43 \\
Flexbeam A Edgewise Bending & \pm 0.35 & \pm 0.82 \\
Flexbeam B Edgewise Bending & \pm 0.30 & \pm 0.71 \\
Flexbeam A Flapwise Bending & \pm 0.24 & \pm 0.56 \\
Flexbeam B Flapwise Bending & \pm 0.42 & \pm 1.00 \\
Blade Shell A Flapwise Bending & \pm 0.20 & \pm 0.50 \\
Blade Shell B Flapwise Bending & \pm 0.23 & \pm 0.56 \\
\hline
\end{tabular}


while those for the sonic anemometer were $12 \mathrm{~Hz}$ and the remainder of the meteorological data were set to 1 $\mathrm{Hz}$. The Neff 470 was synchronized to the SoMat Field Computer in the turbine rotating frame through a discrete signal derived from the digital input/output module and transmitted via wire that passed through a slip ring on the nacelle. The SoMat was programmed to set the discrete positive or high the instant data collection began. When the Neff detected this pulse transitioning from low to high, it would simultaneously initiate collection. The data collected from each system was stored in separate computer files.

\section{Data Processing Subsystem}

The GENPRO processor was used in three passes through the collected data. The first pass merged the two data streams from the rotating (SoMat) and non-rotating frames (Neff 470), applied a signal "despiking" criteria based on the pre-sampling filter characteristics, and stripped out the meteorological and rotor azimuth pulse signal for additional, separate processing. A separate program was written to calculate turbulence quantities such as the instantaneous shearing stresses and fluctuating turbulence components. Further, another program was used to convert the once-per-revolution rotor azimuth pulse into a continuous signal. A second GENPRO pass merged the processed meteorological data and derived rotor azimuth signal with the turbine-related parameters to form a single, scaled data set. This second pass also applied the scaling factors for turbine signals and calculated summary statistics up to the fourth statistical moment for all parameters. A third GENPRO pass was used to generate a range of multi-parameter, timeseries graphic plots in 20-second segments for data review and analysis purposes. The GPP Post-Processor has been used to calculate histograms, frequency spectra, and rainflow cycle-count spectra from the processed time series data.

\section{MEASUREMENT RESULTS}

A series of 19 data records were collected during the period of May 14 through June 1, 1998. Most were 10 minutes in length but two were much shorter due to the turbine shutting down in marginal winds and one (the last) is slightly less than 10 minutes because of the failure of the yaw angle sensor. The inflows for these records covered a wide range of conditions. A statistical summary of these conditions is listed in Table 2. The first three collection periods on June 1st were characterized by a very strong and turbulent flow being shaped by the complex terrain of the Rocky Mountain foothills to the west of the NWTC site. About midway in the first of these periods on June 1st (Run No. 12) the turbine suf- fered a failure in a structural member supporting the nacelle tilt damping mechanism.

\section{Consequences and Source of Tilt Damper Failure}

Prior to the failure of the member supporting the tilt damping mechanism, we noticed that the range of tilt motion was very constrained $\left(\sim \pm 1.5^{\circ}\right)$. Probability density histograms of the tilt angle performance for the 19 data runs are presented in Figure 3. It is clear from this diagram that a major change occurred in the character of the tilt angle activity beginning with Run No. 12 and the strong, turbulent winds of June 1st. Further, the spectral character of the tilt dynamics underwent a systematic shift after Run No. 12 as is demonstrated in Figure 4. While we noticed a change in the tilt angle characteristics during data processing, we did not learn the source of this behavior until three weeks after the conclusion of the tests when the nacelle was opened.

Our investigation revealed that the hydraulic cylinder, which serves as the primary damping mechanism, had been completely filled with oil allowing for no cushioning air pocket. This cylinder is designed with two chambers for the oil to flow back and forth through a small diameter orifice providing a very slow damping action. With the lack of the compressed air cushion and the very low flow rate through the orifice, the tilt damping was minimal and took on essentially the characteristics of a rigid hub turbine. The high loads associated with the very turbulent winds of June 1st caused a fracture of the structural member that was initiated at a high stress concentration on the tilt damper support member.

After the failure, the nacelle tilt had more freedom to move and this is shown in Figures 3 and 4. As a result, we have stratified the results of our analyses into groups before and after the failure. A positive benefit will be to allow us to compare the influence on the turbine dynamics associated with this rigid state with data collected afterwards during periods when the tilt excursion range remains within the original design hard stop limits of $\pm 5^{\circ}$.

\section{Mean Rotorloads Behavior}

Plots of the run mean rotor loads versus hub mean wind speed are presented in Figures 5a-c. Data points prior to and after the tilt mechanism failure are identified. With the exception of the root edgewise bending loads (Figure 5a), a trend line has been fitted through the entire population of points while ignoring the failure stratification and measurement location. In Figures $5 \mathrm{~b}$ and $5 \mathrm{c}$ the mean flapwise loads on the flexible spar and the blade shell to appear to be slightly lower after the failure indicating new paths were established to relieve the loads in the blades. Figure 5a indicates the 
Table 2. Inflow Statistical Summary for Primary Data Collection Period.

\begin{tabular}{|c|c|c|c|c|c|c|c|c|}
\hline $\begin{array}{l}\text { RUN } \\
\text { NO. }\end{array}$ & DATE & $\begin{array}{c}\text { START } \\
\text { TIME } \\
\text { (LDT) }\end{array}$ & $\begin{array}{l}\text { HUB MEAN } \\
\text { WIND SPEED } \\
(\mathrm{m} / \mathrm{s})\end{array}$ & $\begin{array}{l}\text { WIND SPEED } \\
\text { STD. DEV. } \\
(\mathrm{m} / \mathrm{s})\end{array}$ & $\begin{array}{c}\text { TURB. } \\
\text { INTENSITY }\end{array}$ & $\begin{array}{c}\text { POWER } \\
\text { LAW } \\
\text { COEF. }\end{array}$ & $\begin{array}{c}\text { GRADIENT } \\
\text { RICHARDSON } \\
\text { NUMBER } \\
\text { (STABILITY) } \\
\end{array}$ & $\begin{array}{c}\text { HUB } \\
\text { FRICTION } \\
\text { VELOCITY } u_{*} \\
(\mathrm{~m} / \mathrm{s})\end{array}$ \\
\hline 1 & 14 May & $22: 25$ & 6.57 & 0.867 & 0.132 & 0.080 & +0.339 & 0.161 \\
\hline 2 & 15 May & $06: 51$ & 8.68 & 2.100 & 0.242 & 0.031 & +0.008 & 0.312 \\
\hline 3 & 15 May & 08:08 & 14.51 & 2.196 & 0.151 & 0.078 & -0.150 & 0.550 \\
\hline 4 & 15 May & 08:55 & 14.60 & 2.452 & 0.168 & 0.083 & -0.226 & 0.610 \\
\hline 5 & 15 May & $10: 35$ & 12.05 & 2.183 & 0.181 & 0.040 & -0.921 & 0.670 \\
\hline $6^{\#}$ & 15 May & $12: 34$ & 7.84 & 2.362 & 0.301 & 0.087 & -1.693 & 1.010 \\
\hline 7 & 15 May & $13: 27$ & 10.90 & 1.952 & 0.179 & 0.046 & -1.114 & 0.392 \\
\hline 8 & 15 May & $15: 25$ & 9.80 & 1.988 & 0.203 & 0.073 & -1.061 & 0.618 \\
\hline 9 & 15 May & $17: 30$ & 8.45 & 1.439 & 0.170 & -0.008 & -1.846 & 0.515 \\
\hline 10 & 15 May & $20: 54$ & 9.58 & 1.119 & 0.117 & 0.186 & +0.220 & 0.507 \\
\hline $11^{\#}$ & 18 May & $13: 58$ & 5.11 & 1.401 & 0.274 & -0.027 & -4.226 & 0.445 \\
\hline 12 & 01 June & $06: 48$ & 18.33 & 2.806 & 0.153 & 0.173 & +0.031 & 1.372 \\
\hline 13 & 01 June & 07:34 & 18.44 & 3.758 & 0.204 & 0.147 & +0.001 & 1.067 \\
\hline 14 & 01 June & $08: 24$ & 17.40 & 3.904 & 0.224 & 0.154 & -0.028 & 1.460 \\
\hline 15 & 01 June & 09:12 & 12.77 & 2.979 & 0.233 & 0.119 & -0.141 & 0.788 \\
\hline 16 & 01 June & $10: 00$ & 10.23 & 2.740 & 0.267 & 0.102 & -0.363 & 0.863 \\
\hline 17 & 01 June & $10: 51$ & 10.83 & 3.410 & 0.315 & 0.075 & -0.534 & 0.631 \\
\hline 18 & 01 June & $17: 38$ & 8.45 & 1.839 & 0.218 & 0.109 & -0.517 & 0.469 \\
\hline $19^{* *}$ & 01 June & 19:07 & 8.67 & 1.350 & 0.156 & 0.174 & +0.136 & 0.632 \\
\hline
\end{tabular}

\#Early shutdown due to marginal winds.

** Test terminated early due to failure of yaw angle sensor.

increase of the mean edgewise loads on the flexible spar at the root of Blade A increase much more rapidly with wind speed than its counterpart. This difference is significant based on the uncertainties tabulated in Table 1 and reaches about $12 \mathrm{kNm}$ at the rated wind speed of 16 $\mathrm{m} / \mathrm{s}$. A much smaller difference, about $1 \mathrm{kNm}$, can been seen in the flapwise loads of Figures $5 \mathrm{~b}$ and $5 \mathrm{c}$ with no apparent sensitivity to mean wind speed. We believe this difference between the blades reflects a rotor imbalance and is the source of the strong once-per-revolution oscillation seen in the generator power output and many of the load signals.

\section{Characteristics of Power and Structural Loading Oscillation}

In Figure 6 we have plotted 10-second peak-to-peak differences in the output power, normalized by the rated value of $300 \mathrm{~kW}$, against the corresponding wind speed. The entire length of the 19 data records is included. It is clear from this plot the amplitude of the oscillation is definitely related to the wind speed but other factors must be involved. A statistical analysis has revealed that the variation shown in Figure 6 is about equally sensitive to the mean wind speed and the wind speed standard deviation (turbulence). 


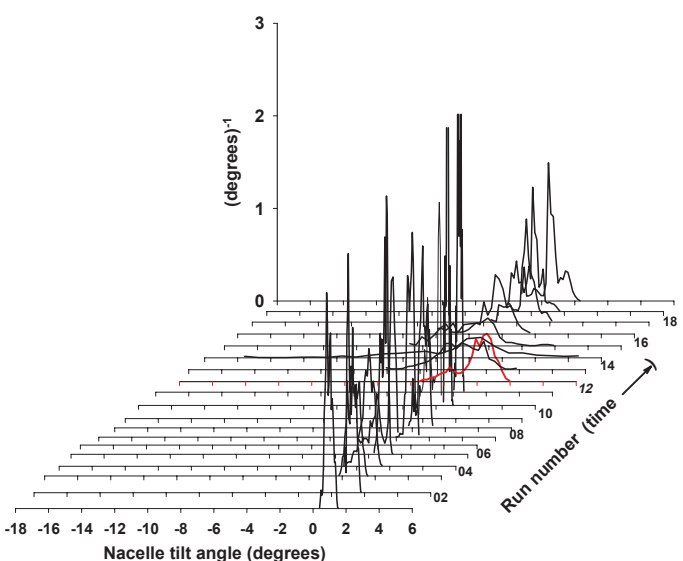

Figure 3. Variation of nacelle tilt angle probability density function with run number.

We examined the characteristics of the flexible spar and shell loads as a function of rotor azimuth. We chose several 20-second records in which the inflow conditions were very steady and there was little or no nacelle yawing motion. The averaged edgewise loads for each blade is plotted as a function of the rotor azimuth angle in Figure 7. In this diagram, Blade $\mathrm{A}$ is down at zero degrees and rotates counterclockwise. The mean wind speed is $6 \mathrm{~m} / \mathrm{s}$ for this record and the inflow contained little turbulence. In such a low and steady wind, the aerodynamic forces are small and reasonably steady which allows the presence of other dynamic influences to be more readily apparent. A pure gravity load on this diagram will produce a locus of points in the shape of a cardioid expressed by an $\mathrm{R} \cos \theta$ function with $\mathrm{R}$ being the gravity moment and $\theta$ the rotor azimuth angle. Setting $\mathrm{R}$ to the observed maximum moments, we have plotted $\mathrm{R} \cos \theta$ curves for each of the blade traces. It can be seen that the locus of Blade B loads follows the gravity-induced cardioid pattern very well. The Blade A trace, however, is larger and deviates significantly from

$1 P \quad 2 P$

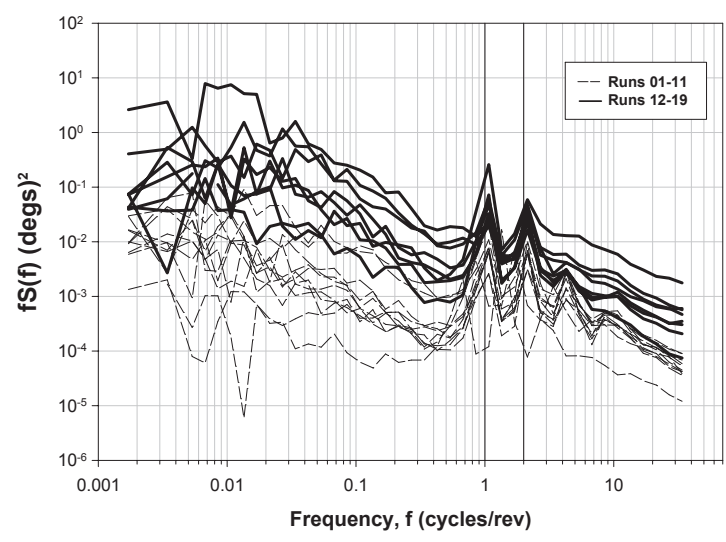

Figure 4. Nacelle tilt angle logarithmic spectra.

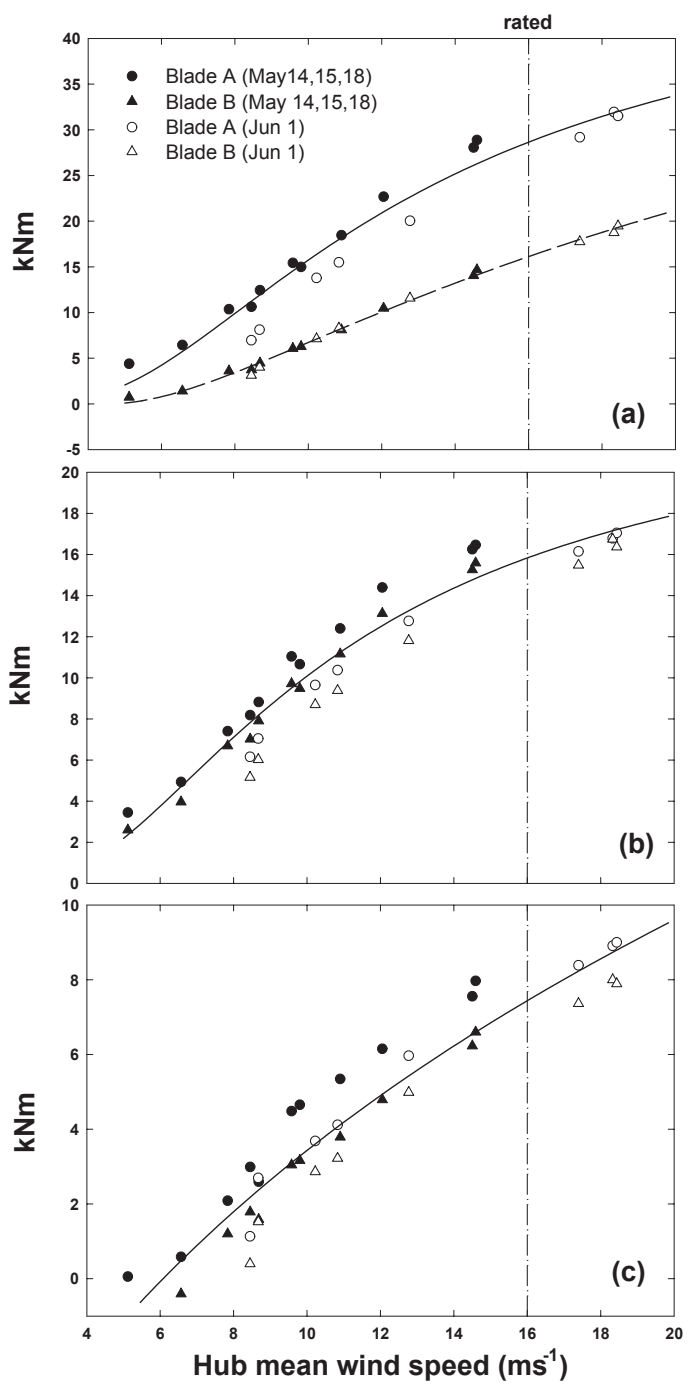

Figure 5. Variation of mean rotor loads with mean wind speed: (a) flexbeam edgewise root bending, (b) flexbeam flapwise root bending, (c) blade shell flapwise bending.

the gravity cardioid particularly in the lower left quadrant. We found that at zero wind speed, the loads on both blades are in agreement with these plots in the horizontal and vertical positions. A large difference is again noted in the polar plot presentation of the flapwise load on the blade shells as shown in Figure 8. We Fourieranalyzed these signals in order to ascertain perhaps where the distortion in the Blade A loading was originating. The corresponding logarithmic frequency spectra for the edge and flapwise signals are plotted in Figure 9 with the frequency axis scaled in cycles per revolution or blade passages (P). It can be seen that the deviation from the pure gravity-cardioid pattern in the Blade A edgewise signal is a consequence of the contribution of a large number of high-order rotational harmonics, particularly the even ones. The difference seen in the 


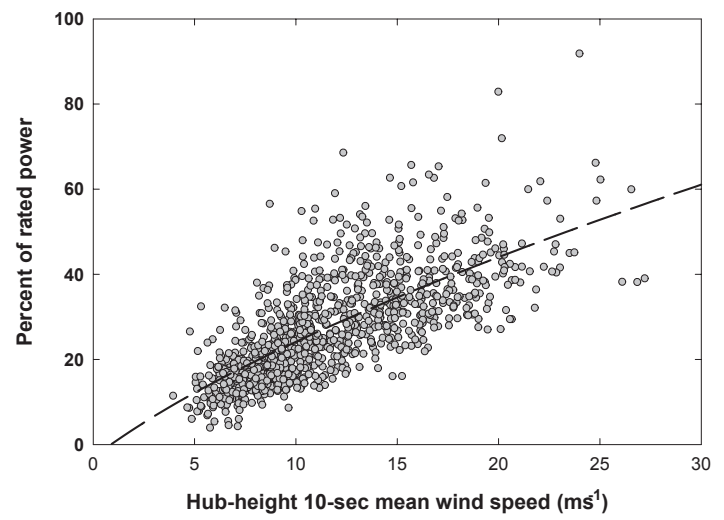

Figure 6. Variation in the difference in peak-to-peak generator power over 10-seconds with the corresponding mean wind speed.

flapwise signal of Figure 8 arises from the high energy in the second rotor harmonic (2P).

We removed the blade shells from the turbine and experimentally determined the center of gravity (c.g.) and weight at that location for each. We found that the c.g. of Blade A was $2.4 \mathrm{~cm}$ closer to the blade root than its counterpart. The blade weights were within $0.36 \mathrm{~kg}$ of each other with Blade A being the heavier at 341.81 $\mathrm{kg}$. This small difference is not statistically significant, however, since the corresponding measurement uncertainty was $\pm 0.41 \mathrm{~kg}$. We compared the weights of the root and tip of each blade and found the root weight of Blade A was $3.86 \pm 0.45 \mathrm{~kg}$ larger than Blade B and this difference is statistically significant at the $95 \%$ confidence level. The tip weight of Blade A was found to be $0.4 \mathrm{~kg}$ larger than Blade B but the difference is not statistically significant.

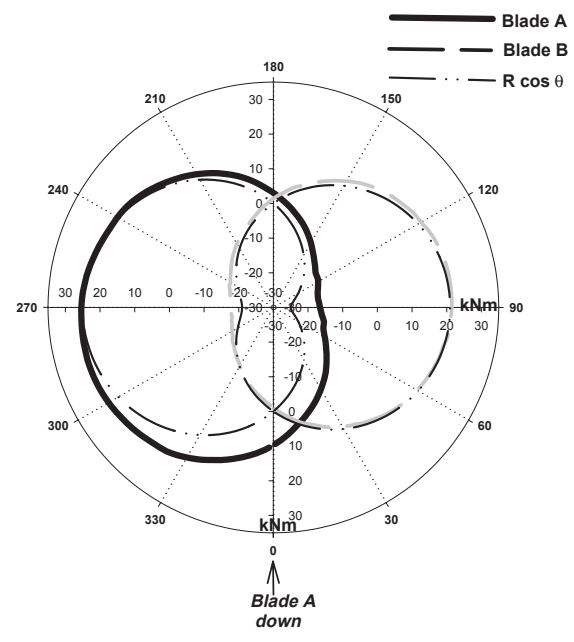

Figure 7. Flexbeam root edgewise loads as a function of the rotor azimuth angle.
These measurements demonstrate that Blade A has a different spanwise mass (and likely a stiffness) distribution than its companion being heavier towards the root and lighter outboard of the c.g. It is possible that with less mass (and possibly less structural stiffness) outboard of the c.g., there will be less centrifugal stiffening during operation which allows larger excursions in the spanwise twist under gravity and turbulence loads. In other words, Blade A structurally (and most likely dynamically) is different from Blade B. Though the spanwise resolution is low, our full system modal testing indicates that Blade A has a greater tendency for twisting outboard than Blade B.

Prior to this final sequence of measurements, we made a significant effort to align both blades to the same static pitch angle. With the advice of Jay Carter, Sr., we

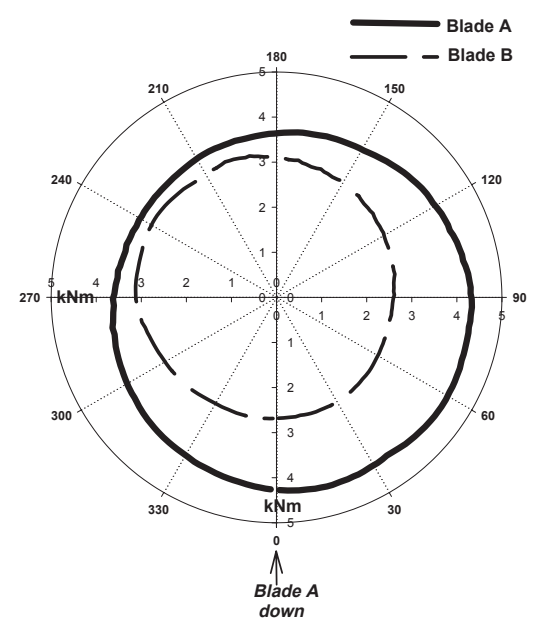

Figure 8. Flexbeam root flapwise loads as a function of the rotor azimuth angle.

applied several techniques to validate the pitch angles. Subsequently, however, we have since learned that our methodology was likely flawed because the position of the reference we were using can vary from blade to blade and could account for up two degrees of error. Thus, while we believe the spanwise structure of Blade $\mathrm{A}$ is contributing to the 1-P oscillation in power and loads, we also believe that a misalignment in the rotor pitch is a distinct possibility. We have and will be studying these issues in our analytical modeling of this turbine (see Wright et al. ${ }^{2}$ )

\section{MEAN LOAD COMPARISON WITH A RIGID-HUB TURBINE}

While we did not collect an extensive amount of data on the NWTC Wind Eagle turbine during this 

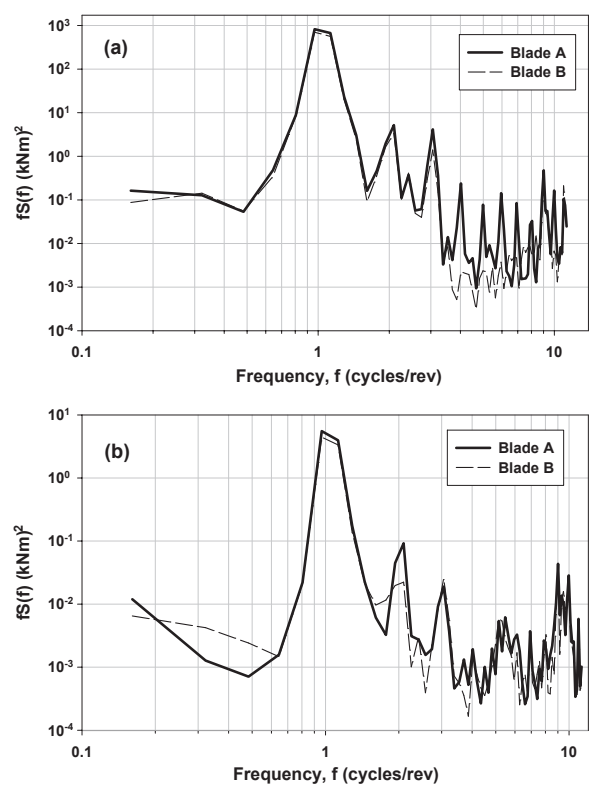

Figure 9. Flexbeam root bending logarithmic spectra:

(a) edgewise; (b) flapwise.

project, we did acquire sufficient information to compare the mean flapwise bending loads with an upwind, three-blade, rigid hub design. In 1990, NREL operated two Micon 65/13 (two-speed generator) turbines sideby-side in a multi-row wind farm in San Gorgonio Pass, California. The turbines were identical except for their rotors. The rotor of one turbine was equipped with NREL (SERI) Thin Airfoil Blades and the other had original-equipment AeroStar blades. The NREL blades were slightly longer than the AeroStar blades but weighed less. The larger swept area of the NREL rotor and lighter, more aerodynamically active blades resulted in higher mean blade flapping loads than its counterpart. The rated wind speeds for the NREL and AeroStar rotors were 12.5 and $16 \mathrm{~m} / \mathrm{s}$ respectively. The rated wind speed for the NWTC Wind Eagle is specified as $16 \mathrm{~m} / \mathrm{s}$.

In order to achieve at least a crude comparison between these two designs, we have normalized the measured mean flapwise loads from each of the Micons and the Wind Eagle by the value of the mean load at the rated wind speed. We have plotted the variation of these normalized loads with wind speed in Figure 10. This diagram appears to demonstrate that the objective of the Wind Eagle flexible design is being met; i.e., to lower loads at high wind speeds. We believe the higher loads associated with the Wind Eagle at the lower wind speeds reflect the lack of pre-coning (it was zero for this turbine) while 9 degrees was built into the Micon rotors. Given the rigidity of the nacelle tilt degree-of-freedom even after the failure, we believe downwind deflection of the rotor blades is the primary contributor to the load reduction seen in Figure 10.

\section{CURRENT IMPRESSIONS}

While more experimental and analytical work is necessary, we would recommend that the turbine designers consider reviewing the fundamental structural design of these very long and flexible blades and the fabrication

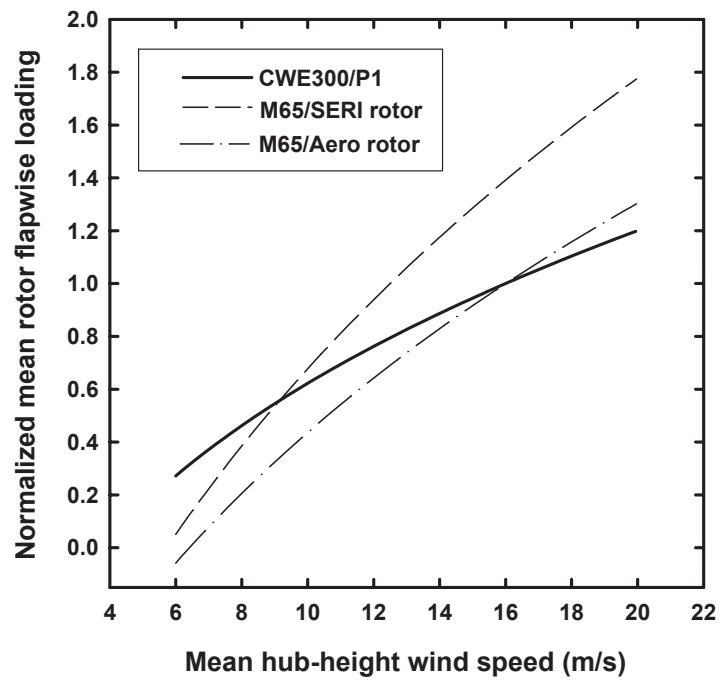

Figure 10. Comparison of normalized mean flapwise bending loads with hub-height mean wind speed. (Normalized by loads at rated wind speed.)

process used to construct them. It is our understanding that earlier and shorter versions of the Wind Eagle rotor blades (except for initial pitch misalignments that were mitigated manually) have not exhibited the characteristics seen in this rotor. Given the evidence presented in this paper and our experience in reproducing these responses analytically, we presently believe that the observed response can be traced to either the design or fabrication procedures or quite possibly both. However, without at least a detailed modal test of each of the blade shells to document any differences, it is unlikely we will achieve an adequate closure of this issue.

\section{FUTURE PLANS}

Using the measured three-dimensional wind data we have developed turbulent inflow simulations for several of the data collection periods listed in Table 2. When complete, we will be using our baseline ADAMS simulation model to assess our ability to predict the response statistics seen in the actual turbine operation. From these results, we will be able to summarize the areas in which we deviate from reality, what the 
potential causes may be, and outline our recommendations for improving our understanding of flexible turbine technology.

\section{ACKNOWLEDGEMENTS}

We thank the staff of the Cannon Wind Eagle Corporation, Dr. Jamie Chapman of the OEM Development Corporation, and Drs. Kevin Jackson and Forrest Stoddard of Dynamic Design for their extensive support of this effort. We sincerely appreciate the advice and counsel received from Mr. Jay Carter, Sr. The project could not have been accomplished without the skills and support afforded us by Ed McKenna and Jim Adams of NREL. We appreciate the discussions and counsel of Dr. Herb Sutherland of the Sandia National Laboratories. We particularly wish to thank the following groups and individuals who made substantial contributions to this project: the Mountain Valley Energy Team of Bob Keller, Todd Longacre, Doug Cook, Grant McFarland, Clay Walter, and Steve Gallegos; Howard McGregor of Engineering Dynamics, Inc; Fong Her of Engineering Dynamics and CarCom, Inc.; Jack Petersen of Martin/Martin Consulting Engineers; Ralph Mangone of Mangone Laboratory, Inc.; and the NREL Site Operations Team for their excellent support in making this effort come to fruition.

\section{REFERENCES}

1. Kelley, N., Wright, A., Bir, G., Osgood, R., McKenna, E., and Sutherland, H., "An Overview of the NREL/SNL Flexible Turbine Characterization Project," 17th ASME/AIAA Wind Energy Symposium, NREL/CP500-24046, Golden, CO: National Renewable Energy Laboratory, September 1998.

2. Wright, A. D., Kelley, N. D., and Osgood, R. M., "Validation of a Model for a Two-Bladed Flexible Turbine Rotor System," 18th ASME/AIAA Wind Energy Symposium, in publication, 1999.

3. Elliot, A. S., and Wright, A. D., "ADAMS/WT: An Industry-Specific Interactive Modeling Interface for Wind Turbine Analysis," Wind Energy 1994, Musial, Hock, and Berg (eds.) SED-Vol. 14, New York, ASME, pp. 111-122, 23-26 January 1994.

4. Wilson, R. E., Freeman, L. N., Walker, S. N., and Harman, C. R., FAST Advanced Dynamics Code, TwoBladed Teetered Hub Version 2.4 User's Manual, Final Report. Golden, CO: NREL, March 1996. Work performed by Oregon State University, Corvallis, OR.
5. Hansen, A. C. User's Guide to the Wind Turbine Dynamics Computer Programs YawDyn and AeroDyn for $A D A M S \circledR$ Version 9.6. Salt Lake City, UT: University of Utah, June 1996.

6. Gacnik, B. and Lackman, R. General Scientific Data Processor - User Guide. NCAR/TN-208+1A, Boulder, CO: National Center for Atmospheric Research, 1983.

7. Buhl, M. L., Jr. GPP User's Guide, A General Purpose Postprocessor for Wind Turbine Data Analysis. NREL/TP-442-7111. Golden, CO: National Renewable Energy Laboratory, 1995.

8. Makena, P. V. and Osgood, R. M., Cannon Wind Eagle (CWE-300) Wind Turbine with 96 Foot Rotor: A Full-Modal Survey, Preliminary Report (in preparation). Golden, CO: NREL, December 1997. 